\title{
Application of failure mode and effects analysis to minimize quality failures in clinical biochemistry laboratory
}

\author{
Boinapalli Sudhakar', Bhavesh R. Sadariya,"* \\ ${ }^{\mathbf{1}}$ Associate Professor, ${ }^{\mathbf{2}}$ Assistant Professor, Dept. of Biochemistry, Pacific Institute of Medical Sciences, Udaipur, \\ Rajasthan, India \\ *Corresponding Author: Bhavesh R. Sadariya \\ Email: dr.bhaveshsadariya1988@gmail.com
}

Received: $4^{\text {th }}$ June, 2018

Accepted: $26^{\text {th }}$ July, 2018

\begin{abstract}
Introduction: Quality failures in the clinical laboratories should be analyzed to improve patient safety in hospital. Purpose of this study is to apply failure mode and effects analysis (FMEA) for prospective risks of quality failures and appropriate corrective actions to reduce/prevent errors in clinical biochemistry laboratory.

Materials and Methods: Members of multidisciplinary team were trained to notify quality failures. Each quality failures assigned value from 1 to 5 based on severity, occurrence and detection of failure modes. Risk priority number (RPN) was calculated from severity, occurrence and detection scores (RPN = SI x OI x DI). For highest risk failure modes, FMEA tool was applied in two stages: before and after action plan.

Results: A total 14 high risk failure modes were found and arranged based on their RPN values from high to low score. In 5 highest risk failure modes RPN values before action plan were as follows: Transcription error (RPN=100), Malfunction of reagent $(\mathrm{RPN}=75)$, Malfunction of calibrator $(\mathrm{RPN}=48)$, Samples taken in wrong tubes $(\mathrm{RPN}=36)$ and Sample misplaced in laboratory (RPN=36). After corrective actions taken, we found decrease in RPN values for 5 highest risk failure modes.

Conclusion: FMEA is an effective tool to reduce quality failures in clinical biochemistry laboratories.
\end{abstract}

Keywords: Failure mode and effects analysis (FMEA), Quality failure, Patient safety, Risk priority number (RPN).

\section{Introduction}

Clinical laboratories are essential part of health care system as they help in appropriate diagnosis of patient's health. Clinical laboratory working process is a complex procedure which may associate with certain errors. Presently the term "quality failure" is used instead of errors/mistakes/blunders in clinical laboratories. ${ }^{1}$ Effective patient treatment and patient safety can be improved by prevention and detection of quality failures at the time of occurrence. Occurrence of quality failures can be assessed by person approach and system approach. Person approach includes incident reporting or detection of quality failure and system approach is proactive methods like failure mode and effect analysis (FMEA). ${ }^{2}$

FMEA method was first used in aerospace engineering to detect rudiments that might cause harm and to prioritize corrective measures for evaluation of complex processes. ${ }^{3-5}$ FMEA tracks the system based approach mainly focus on the design of the system where primary aim is to prevent quality failures. ${ }^{6}$

FMEA model has been used in various areas of medical field to improve patient safety before substantial damage occurs. ${ }^{7-9}$

FMEA model helps to identify quality failures, their effects and risks with their reduction/ elimination, which depends on three factors: i) severity (consequence of failure/ degree of harm to the patient), ii) probability (frequency of failure occurrence) and iii) detection (ability to detect the failure before patient harm occurs.
The aim of the present study was to implement FMEA tool in clinical biochemistry laboratory for evaluating high risk processes prone to failure before their occurrence.

\section{Materials and Methods}

This study was conducted at clinical biochemistry laboratory, Pacific institute of medical sciences (PIMS), Udaipur. The study was approved by institutional ethics committee of PIMS, Udaipur. Clinical biochemistry laboratory receives an average of 6040 samples per month.

Clinical laboratory processes includes receiving of labeled sample with test requests on requisition form, centrifugation, analysis of sample in fully automated analyzer, manually transfer results from analyzer to laboratory software, report generation, authorization and dispatch to the consultants. A multidisciplinary team consisting of health care professionals i.e. laboratory staff, nurses and clinicians form different departments were recruited and trained to notify quality failures. Quality failures were documented under three main headings: Description of failure, reasons for failure, action to be taken.

Reported quality failures assigned values from 1 to 5 based on severity $(\mathrm{S})$, occurrence $(\mathrm{O})$ and detection (D) as given in Table $1 .{ }^{10}$ Risk priority number (RPN) was calculated from severity, occurrence and detection scores $(\mathrm{RPN}=\mathrm{SI} \times \mathrm{OI} \times \mathrm{DI})$. RPN is helpful in identification of high risk failures modes requiring priority measures. 


\section{Results}

During entire study period, a total number 14 high risk failure modes identified in clinical biochemistry laboratory as depicted in Table 2. Risk priority number (RPN) was calculated from severity, occurrence and detection ratings for each failure modes. Failures with high RPN values occurred in following phases: transcription error (wrong entry of result), malfunction of reagent, malfunction of calibrator, samples taken in wrong tubes and sample misplaced in laboratory (Table 2).

Initial FMEA analysis was done with highest risk failure modes and strategized to minimize failures as depicted in Table 3. After failure detection process, corrective actions were taken and FMEA analysis was done. Table 4 and Fig. 1 shows decrease RPN values for failure modes after corrective actions.

Table 1: Criteria for failure mode and effect analysis rating ${ }^{10}$

\begin{tabular}{|c|c|c|}
\hline Criterion & Rating & Description \\
\hline \multicolumn{3}{|r|}{ Severity } \\
\hline Negligible & 1 & No adverse clinical outcome: Unchanged patient management \\
\hline Minor & 2 & $\begin{array}{l}\text { No adverse clinical outcome: Minor change in patient management } \\
\text { e.g. short delay in diagnosis due to delay in reporting test result }\end{array}$ \\
\hline Moderate & 3 & $\begin{array}{l}\text { Minor adverse clinical outcome } \\
\text { e.g. need for an additional venepuncture }\end{array}$ \\
\hline Critic & 4 & $\begin{array}{l}\text { Moderate adverse clinical outcome } \\
\text { e.g. on basis of incorrect blood glucose result patient started on hypoglycemic } \\
\text { medication }\end{array}$ \\
\hline Catastrophic & 5 & $\begin{array}{l}\text { Significant adverse clinical outcome } \\
\text { e.g. significant morbidity, mortality }\end{array}$ \\
\hline \multicolumn{3}{|r|}{ Occurrence } \\
\hline Remote & 1 & Failure occurs annually \\
\hline Uncommon & 2 & Failure occurs within 2-6 months \\
\hline Occasional & 3 & Failure occurs monthly \\
\hline Frequent & 4 & Failure occurs weekly \\
\hline Continuous & 5 & Failure occurs daily \\
\hline \multicolumn{3}{|r|}{$\begin{array}{c}\text { Detection } \\
\end{array}$} \\
\hline High & 1 & Failure always detected immediately \\
\hline Occasional & 2 & Failure detected intermittently at the moment of occurrence \\
\hline Moderate & 3 & Modest failure detection at the moment of occurrence \\
\hline Low & 4 & Lowest failure detection at the moment of occurrence \\
\hline Nil & 5 & No failure detection at the moment of occurrence \\
\hline
\end{tabular}

Table 2: High risk failure modes with their RPN

\begin{tabular}{|l|l|c|c|c|c|}
\hline S. No. & \multicolumn{1}{|c|}{ Quality failure } & SI & OI & DI & RPN \\
\hline 1 & Transcription error (Wrong entry of result) & 5 & 5 & 4 & 100 \\
\hline 2 & Malfunction of reagent (Contaminated) & 5 & 3 & 5 & 75 \\
\hline 3 & Malfunction of calibrator (Contamination) & 4 & 3 & 4 & 48 \\
\hline 4 & Samples taken in wrong tubes & 3 & 4 & 3 & 36 \\
\hline 5 & Sample misplaced in laboratory & 3 & 3 & 4 & 36 \\
\hline 6 & Incorrect sample (Hemolysis/Lipemia) & 4 & 5 & 1 & 20 \\
\hline 7 & Refrigerator failure & 4 & 1 & 5 & 20 \\
\hline 8 & Non reporting of critical result to clinician & 5 & 4 & 1 & 20 \\
\hline 9 & Improper centrifugation & 2 & 3 & 2 & 12 \\
\hline 10 & Breakdown of analyzer & 5 & 2 & 1 & 10 \\
\hline 11 & $\begin{array}{l}\text { Wrong/incomplete labelled sample/ } \\
\text { requisition form }\end{array}$ & 2 & 2 & 1 & 4 \\
\hline 12 & Wrong entry of patient record on LIS & 1 & 2 & 2 & 4 \\
\hline 13 & Wrong test ordered & 1 & 1 & 4 & 4 \\
\hline 14 & Missing entry of investigation value & 1 & 2 & 1 & 2 \\
\hline
\end{tabular}

SI: Severity index, OI: Occurrence index, DI: Detection index, RPN: Risk priority number, LIS: Laboratory information system 
Table 3 Initial FMEA analysis with highest risk failure modes (before action plan)

\begin{tabular}{|l|c|c|c|c|c|c|c|c|}
\hline Failure mode & $\begin{array}{c}\text { Potential } \\
\text { Effect }\end{array}$ & SI & $\begin{array}{c}\text { Potential } \\
\text { Cause }\end{array}$ & OI & $\begin{array}{c}\text { Control } \\
\text { measure }\end{array}$ & DI & RPN & Action taken \\
\hline $\begin{array}{l}\text { Transcription } \\
\text { error (Wrong } \\
\text { entry of result) }\end{array}$ & $\begin{array}{c}\text { Useless } \\
\text { result }\end{array}$ & 5 & Inefficient staff & 5 & $\begin{array}{c}\text { Efficient staff } \\
\text { training }\end{array}$ & 4 & 100 & $\begin{array}{c}\text { Staff training } \\
\text { was given }\end{array}$ \\
\hline $\begin{array}{l}\text { Malfunction of } \\
\text { reagent }\end{array}$ & $\begin{array}{c}\text { Useless } \\
\text { result }\end{array}$ & 5 & Contamination & 3 & $\begin{array}{c}\text { IQC before } \\
\text { sample analysis }\end{array}$ & 5 & 75 & $\begin{array}{c}\text { IQC before } \\
\text { and after run }\end{array}$ \\
\hline $\begin{array}{l}\text { Malfunction of } \\
\text { calibrator }\end{array}$ & $\begin{array}{c}\text { Calibratio } \\
\text { n failure }\end{array}$ & 4 & $\begin{array}{c}\text { NC storage } \\
\text { temperature }\end{array}$ & 3 & $\begin{array}{c}\text { Visual check of } \\
\text { calibrator }\end{array}$ & 4 & 48 & $\begin{array}{c}\text { Continuous } \\
\text { Temperature } \\
\text { monitoring of } \\
\text { refrigerator }\end{array}$ \\
\hline $\begin{array}{l}\text { Samples taken } \\
\text { in wrong tubes }\end{array}$ & $\begin{array}{c}\text { Wrong } \\
\text { result }\end{array}$ & 3 & Inefficient staff & 4 & $\begin{array}{c}\text { Efficient staff } \\
\text { training }\end{array}$ & 3 & 36 & $\begin{array}{c}\text { Staff training } \\
\text { was given }\end{array}$ \\
\hline $\begin{array}{l}\text { Sample } \\
\text { misplaced in } \\
\text { laboratory }\end{array}$ & $\begin{array}{c}\text { Delayed } \\
\text { reports }\end{array}$ & 3 & Inefficient staff & 3 & $\begin{array}{c}\text { Efficient staff } \\
\text { training }\end{array}$ & 4 & 36 & $\begin{array}{c}\text { Staff training } \\
\text { was given }\end{array}$ \\
\hline
\end{tabular}

Table 4: FMEA analysis after implementing the action plan with highest risk failure modes

\begin{tabular}{|l|c|c|c|c|c|c|c|}
\hline Failure mode & Potential Effect & SI & Potential Cause & OI & Control measure & DI & RPN \\
\hline $\begin{array}{l}\text { Transcription error } \\
\text { (Wrong entry of } \\
\text { result) }\end{array}$ & Useless result & 5 & Inefficient staff & 2 & $\begin{array}{c}\text { Efficient staff } \\
\text { training }\end{array}$ & 1 & 10 \\
\hline $\begin{array}{l}\text { Malfunction of } \\
\text { reagent }\end{array}$ & Useless result & 5 & Contamination & 1 & $\begin{array}{c}\text { IQC before sample } \\
\text { analysis }\end{array}$ & 2 & 10 \\
\hline $\begin{array}{l}\text { Malfunction of } \\
\text { calibrator }\end{array}$ & $\begin{array}{l}\text { Incorrect results due } \\
\text { to Calibration failure }\end{array}$ & 4 & $\begin{array}{c}\text { NC storage } \\
\text { temperature }\end{array}$ & 1 & $\begin{array}{c}\text { Visual check of } \\
\text { calibrator }\end{array}$ & 1 & 4 \\
\hline $\begin{array}{l}\text { Samples taken in } \\
\text { wrong tubes }\end{array}$ & Wrong result & 3 & Inefficient staff & 2 & $\begin{array}{c}\text { Efficient staff } \\
\text { training }\end{array}$ & 2 & 12 \\
\hline $\begin{array}{l}\text { Sample misplaced } \\
\text { in laboratory }\end{array}$ & Delayed reports & 3 & Inefficient staff & 1 & $\begin{array}{c}\text { Efficient staff } \\
\text { training }\end{array}$ & 1 & 3 \\
\hline
\end{tabular}

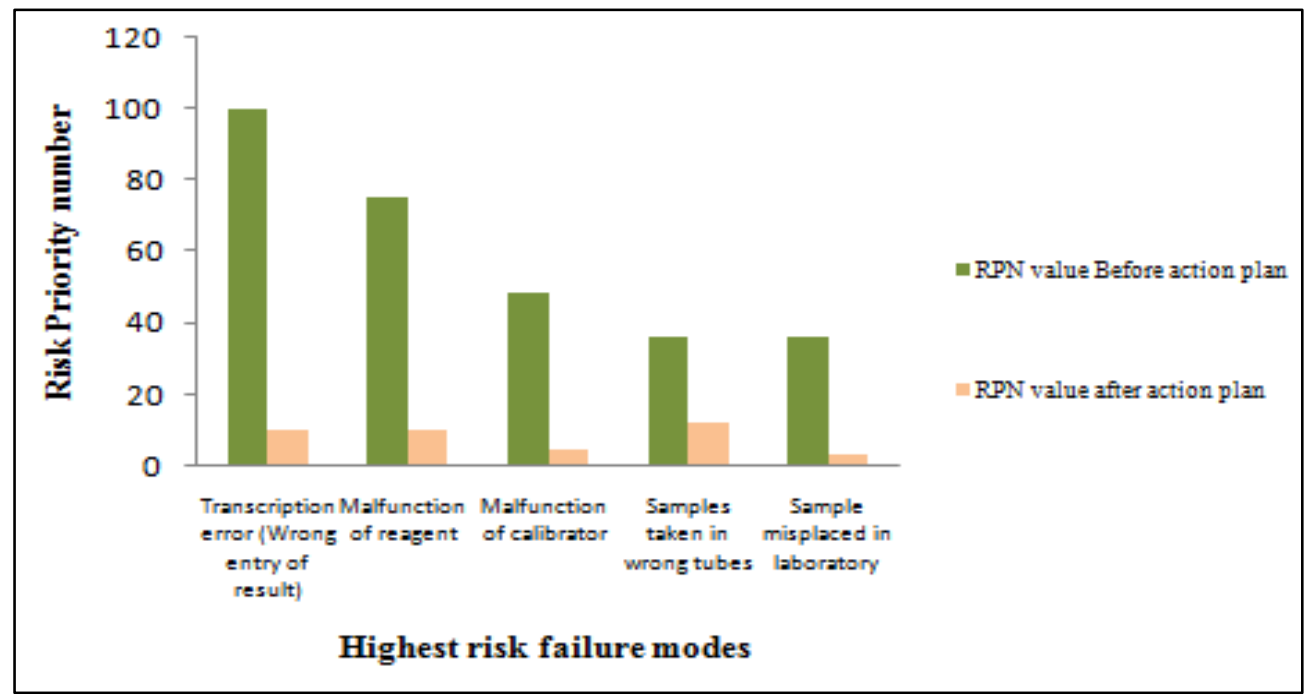

Fig. 1: Risk priority number of highest risk failure modes before and after action plan

\section{Discussion}

Reducing the errors and their risks in clinical laboratories is a great challenge to improve the patient safety. Laboratory failure identification process and corrective actions must be established to minimize the potential errors. ${ }^{11,12}$ In clinical laboratories, probable risk analysis for high risk processes can be assessed with the help of FMEA tool. RPN values were calculated for identified high risk failure modes. The most five serious failures were analyzed to find out the potential causes, effects and appropriate actions to minimize the failures. 
In our study, RPN values for failure modes like transcription errors, samples taken in wrong tubes and samples misplaced in laboratory were improved by effective staff training. With the use of effective temperature monitoring and IQC run before-after sample analysis helps to reduce RPN values for failure mode like malfunction of calibrators and reagents, respectively. After execution of the action plan, FMEA analysis shows RPN values less in numbers, which helps the staff to record failure modes for future analysis and thus improve the quality.

As compared to other prospective risk analysis methods, FMEA analysis provides solution for high risk failure modes in clinical laboratories. ${ }^{13}$ Research conducted by Lao EG et al in 2017 supports results of this study. ${ }^{14}$

\section{Conclusion}

Conclusively, FMEA is a proactive tool helps to solve potential failure modes and adverse events by taking corrective actions in clinical biochemistry laboratory.

\section{Acknowledgement}

The authors are grateful to the clinical staff of biochemistry laboratory, Pacific Institute of Medical Sciences, Udaipur for their support during the study. Author declares no conflict of interest.

\section{References}

1. O'Kane MJ, Lynch PLM, McGowan N. The development of a system for reporting, classification and grading of quality failures in the clinical biochemistry laboratory. Ann Clin Biochem. 2008;45:129-134.

2. O'kaine M. The reporting, classification and grading of quality failures in the medical laboratory. Clin Chem Acta. 2009; 404:28-31.

3. Joint Commission Resources. Failure Mode and Effects Analysis in Health Care: Proactive Risk Reduction. 3rd ed. Oak Brook, IL: Joint Commission International; 2010.

4. Joint Commission on Accreditation of Healthcare Organizations An introduction to FMEA. Using failure mode and effects analysis to meet JCAHO's proactive risk assessment requirement. Failure Modes and Effect Analysis. Health Devices. 2002;31:223-226.
5. Sharma RK, Kumar D, Kumar P. Systematic failure mode effect analysis (FMEA) using fuzzy linguistic modeling. Int J Qual Reliab Manage. 2005;22:986-1004.

6. Cohen MR, Sanders J, Davis NM. Failure mode and effects analysis: a novel approach to avoiding dangerous medication errors and accidents. Hosp Pharm. 1994;29:319-330.

7. Lu Y, Teng F, Zhou J, Wen A, Bi Y. Failure mode and effect analysis in blood transfusion: a proactive tool to reduce risks. Transfusion. 2013;53:3080-3087.

8. Uslan MM, Burton DM, Chertow BS, Collins R. Accessibility of insulin pumps for blind and visually impaired people. Diabetes Technol Ther. 2004;6:621634.

9. Arenas VJJ, Gomez SA, Nieto GM and Faus FV. Using failure mode and effects analysis to improve the safety of neonatal parenteral nutrition. Am J Health Syst Pharm. 2014;71(14):1210-8.

10. Mendes ME, Ebner PA, Romano P, Neto MP, Sant'anna A and Sumita NM. Practical aspects of the use of FMEA tool in clinical laboratory risk management. J Bras Patol Med Lab. 2013;49(3):174-181.

11. Plebani M, Carraro P. Mistakes in a stat laboratory: types and frequency. Clin Chem. 1997;43:1348-51.

12. Nakhleh RE. Disclosure of errors in pathology and laboratory medicine. Am J Clin Pathol. 2011;135:666-7.

13. Potts HW, Anderson JE, Colligan L, Leach P, Davis S, Berman J. Assessing the validity of prospective hazard analysis methods: a comparison of two techniques. $B M C$ Health Serv Res. 2014;14:41.

14. Lao EG, García ÁS, Figuerola MB, Moreno E and Paraire $\mathrm{AH}$. Errors of clinical laboratory and its impact on patient safety. Open Journal of Social Sciences. 2017;5:243-253.

How to cite this article: Sudhakar B, Sadariya B. R. Application of failure mode and effects analysis to minimize quality failures in clinical biochemistry laboratory. Int $\mathrm{J}$ Clin Biochem Res. 2018;5(4):613-616. 